\section{REPORTING VERBS AND RELATED SYNTACTIC CHOICES IN STUDENTS' THESES: A STUDY OF TWO DISCIPLINES}

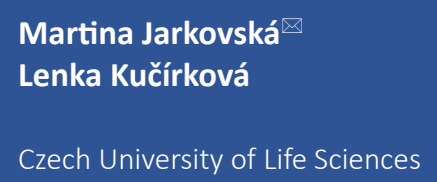

Prague, Czech Republic

\section{jarkovska@pef.czu.cz}

\begin{abstract}
Adopting Hyland's (2002) framework of reporting words (RVs), the paper investigates the use of RVs in Master's theses written in English by students of two disciplines, Economics and Management and Natural Resources. The data were drawn from two sub-corpora, each consisting of 82 Literature Reviews, where other authors' research is summarised and commented on. Besides determining the most frequent communicative functions, in this paper, the RVs are further analysed in terms of the verb tense, voice, and subject-agent. The findings revealed significant differences between the two disciplines. In the former, most RVs were in the present active with named-author as the subject, conveying a neutral attitude towards the reported message and neutrally summarising previous research outcomes. Most RVs were in the past tense in the latter, reporting on past research procedures or outcomes. The findings reveal infrequent use of evaluative or critical verbs. Each discipline's predominant choice may suggest writers' lower ability to highlight the cited sources' direct relevance to their research. The study hopes to contribute to the efficacy of teaching English for Academic Purposes to non-native speakers. It has pedagogical implications for academic writing in both undergraduate and postgraduate courses at non-philological tertiary education institutions.
\end{abstract}

\section{KEYWORDS}

Cited author, integral citation, literature review, reporting citation, reporting verb

\section{HOW TO CITE}

Jarkovská M., Kučírková L. (2021) 'Reporting Verbs and Related Syntactic Choices in Students' Theses: A Study of Two Disciplines', Journal on Efficiency and Responsibility in Education and Science, vol. 14, no. 3, pp. 130-142. http://dx.doi.org/10.7160/ eriesj.2021.140301

\section{Article history}

Received

June 15, 2020

Received in revised form

January 24, 2021

Accepted

July 2, 2021

Available on-line

September 30, 2021

\title{
Highlights
}

- Types and functions of reporting verbs in students' undergraduate theses analysed.

- Use of verb tense and voice in the integral citations with reporting verbs identified.

- Expressions of the cited author in integral citations with reporting verbs categorised.

\section{INTRODUCTION}

The paper examines the use of reporting verbs (RVs) in the citation. Citing the work of others is a significant part of academic discourse, and RVs unarguably belong among its most essential features. While citing, writers often use RVs to present, criticise or dispute other writers' opinions and claims, and express their own (Hyland, 1999).

There have been many studies conducted on the citation structure (e.g. Hyland, 1999; Swales, 1990) or the function of citation (e.g. Harwood, 2009; Hyland, 1999; Jomaa and Bidin, 2016; Mansourizadeh and Ahmad, 2011; Petrić and Harwood, 2013; Swales, 1990). Swales (1990) was the first to make a distinction between an integral and non-integral citation. The former contains the name of the reported researcher in the grammar of the reporting sentence and emphasises the messenger, e.g. "Swales (1990) makes a distinction..." The latter refers to the researcher only in parenthesis or superscript numbers, emphasising the reported massage (Lee, Hitchcock and Casal, 2018). Swales (1990) further distinguished between reporting citations, including RVs, and non-reporting citations that did not. Although the citation conventions (author/date and numerical) might affect the writer's choice between citation patterns, it is noted that the citation pattern choices, as well as the choices of RVs in reporting structures, can mainly be attributed to disciplinary differences (Hyland, 1999; Hyland and Jiang, 2017). This paper focuses on RVs in reporting structures irrespective of the (non) integrity or the citation conventions used.

The research was conducted on Literature Review sections of Master theses written in English by second language (L2) 
learners, university students of two disciplines, Economics and Management and Natural Resources, at the Czech University of Life Sciences Prague (CULS Prague). According to SolerMonreal and Gil-Salom (2011), it is this section of a thesis where citations are mostly found, presenting historical background, discussing theories and concepts, showing related research, and clarifying terminology concepts parallel with the context of the research (Ridley, 2008). The objective was to determine how frequently the students used specific RVs and their evaluative functions and how significant the difference was in their usage between the two disciplines. Another objective was to provide us with better insight into students' performance when writing their Master's theses in English. As Bloch (2010) points out, for L2 learners, it is often difficult to choose the RVs that can both meet the syntactic requirements of the reporting sentence and, at the same time, express their attitudes toward the reported claims. Although RVs are one of the essential items in writing statements for academic writing (Hyland, 1998), the findings from the research performed on students' academic writing (Ramoroka, 2014) and Master's theses in particular (Manan and Noor, 2014, 2015; Nguyen and Pramoolsook, 2015, 2016) show that students are not always fully aware of how to use RVs appropriately. Besides the semantic evaluation of the RVs, the paper's focus was also on the syntactic aspects of the structures containing the RVs, i.e. the choice of the verb tense and voice used in the predicate and the choice of the sentence subject-agent.

\section{Reporting verbs}

RVs have been investigated in terms of their types and functions (Thompson and Ye, 1991; Thomas and Hawes, 1994; Hyland, 2002), tense choices (Hawes and Thomas, 1997; Swales and Feak, 2004) or semantic evaluation (Hyland, 2002; Petrić and Harwood, 2013; Swales, 2014), providing beneficial academic writing implications and introducing criteria for categorising RVs in the academic setting. One of the most insightful categorisation frameworks was introduced by Hyland (1999, 2002). Drawing from previous classification frameworks (Thompson and Ye, 1991; Thomas and Hawes, 1994), Hyland (1999) categorised RVs into three main functional types as Research Acts indicating experimental activity carried out in the real world (e.g. observe, discover, show), Cognition Acts associated with the researcher's mental processes (e.g. believe, suspect, assume), and Discourse Acts concerned with linguistic activities focusing on the verbal expression of cognitive or research activities (e.g. discuss, report, state). Hyland's (2002) model, adopted for this study, is summarised in Figure 1.

Reporting

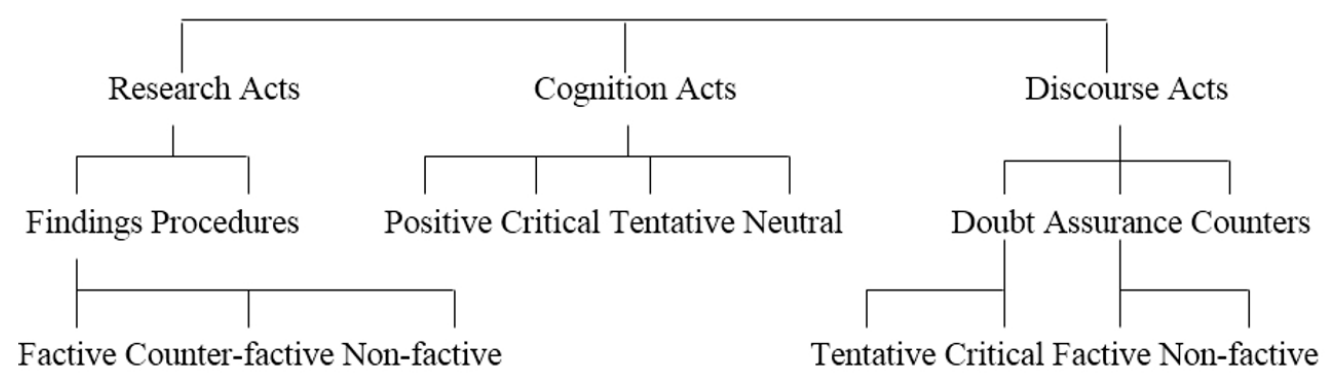

Figure 1: Categories and subcategories of reporting verbs (Hyland, 2002: 119)

Dividing each type of RVs into minor subsets based on their evaluative function in the discourse - unlike his predecessors (Thompson and Ye, 1991; Thomas and Hawes, 1994), Hyland (2002) introduces another perspective, the writer. In citations, writers can thus take either a supportive, tentative, critical, or neutral stance towards the reported claim and vary their commitment by employing RVs, which imply a personal stance (e.g. show, demonstrate) or attribute a position to the cited author (e.g. accuse, believe).

Unlike previous studies (Thompson and Ye, 1991; Thomas and Hawes, 1994), Hyland (1999, 2002) draws conclusions from multi-disciplinary research. As Hyland (1999) claims, the categorisation cannot be considered "watertight" as it allows for overlaps among the categories. For example, agree, categorised as a cognitive verb, implies a strong verbal expression, a characteristic feature of discourse verbs. Similarly, analyse, a procedural Research Act verb may refer to mental processes and classify as a cognition verb. Nevertheless, such „inconsistencies” may not necessarily cause ambiguities regarding the verb's primary function in context. Thus, the framework categorising RVs into processes whose evaluative functions are further sub-categorised according to the writer's stance towards the reported message seems best suited for analysing the student-writer's understanding of the cited context.

\section{Other ways of examining reporting verbs}

Another way of examining RVs is by exploring their syntactic patterns. Besides classifying types and functions of RVs (Thomas and Hawes, 1994), in further research performed on articles from the Journal of Psychosomatic Medicine, Hawes and Thomas (1997) found that the leading choices for the verb in reporting sentences were the past tense in the active voice, followed by present tense and present perfect active and passive. Moreover, the tense choice correlated with RVs' categorisation into discourse and non-discourse verbs (Thomas and Hawes, 1994). Citations with RVs in the past tense and 
with the researcher's name as the subject provide particulars for a previous generalisation or a claim, while citations with the verb in the present tense communicate generalised interpretations and suggest the writer's commitment to the reported information. The present perfect tense in citations usually highlights previous studies' relevance to the writer's research write-up (Hawes and Thomas, 1997). Likewise, Swales and Feak (2004) stated that the past tense was used to refer to single studies, the present tense referred to an inquiry area, and the present perfect tense was preferred when referring to current knowledge. It could be noted that the distinction between past and present is rather citation-specific. For instance, the difference in meaning between "find" and "found", non-factively commenting on research findings, might be insignificant, depending on the time frame between the original and reported message. In contrast, with a cognition RV "believe" portraying the cited material in terms of mental processes, the used tense could imply a significant meaning difference. The present perfect is usually used to refer to a body of cited research that is being summarised.

In another classification, Thompson (2005) categorised reporting citations according to their contextual functions. The Verb Controlling category emphasised the RV rather than a cited author in the subject's position in the active clause, e.g. "Thomson (2005) categorised..." In the Naming category, the emphasis was instead on the cited author referred to in a noun phrase, e.g. " ...another categorisation is shown in Thomson (2005)". The rhetorical functions of citations irrespective of their (non)-integrity were further analysed, e.g. by Harwood (2009) and Petrić and Harwood (2013).

In Swales' (2014) classification of reporting citations, the cited author has either a role of the sentence subject, e.g. "Swales (2014) indicates...", adjunct, e.g. “... was indicated by Swales (2014) or can be a part of a noun phrase depending on the level of integration into the clause structure. Adopting the Functional Theory approach and enhancing Swales' (2014) classification, Jomaa and Bidin (2016) identified the cited author's role in clauses of integral citations under the interpersonal meanings as the subject, adjunct, and complement. Under experiential meanings associated with the verb types, represented by, e.g. mental, verbal or behavioural processes, Jomaa and Bidin (2016) identified as many as thirteen functional roles of the cited author, among them the most dominant "Sayer", "Actor", or "Senser". The roles of the cited author under the experiential meanings conflate with the roles of the cited author under the interpersonal meanings, i.e. "Sayer", "Actor", and "Senser" as the subject in active clauses. In passive clauses, the cited author functions as an "Agent" and corresponds with the author's functional role as the adjunct (Jomaa and Bidin, 2016).

\section{Genre studies on reporting verbs across disciplines}

Besides investigating the types, functions, syntactic aspects and semantic evaluation of RVs, research has focused on using RVs in the citation in various genres or disciplines. Much research has been performed on research articles (RAs), a pre-eminent research genre in many disciplines (Hyland, 1998). According to Hyland (1999), RVs are more frequent in soft disciplines (e.g. humanities), where they allow writers to show their stance and evaluation, rather than in hard disciplines (e.g. biology, chemistry) where non-integral citations prevail. Similarly, Thompson and Tribble (2001), Hyland and Jiang (2017) and Uba (2020) attribute a higher use of RVs in soft disciplines to the nature of disciplinary discourse, where a certain level of subjectivity is prevalent. Jafarigohar and Mohammadkhani (2015) compared RVs in applied linguistics RAs by nonnative and native English writers, while Mansourizadeh and Ahmad (2011) examined RVs in chemical engineering RAs by non-native experts and non-native novice writers. Both studies confirm the higher frequency of RVs to synthesise reported material in native and non-native expert writing. Agbaglo (2017) investigated RVs' use in the university Department of English lecturers' RAs, showing a preference for Discourse Acts types compared to less frequently used Research Acts and the Cognitive Acts categories (Hyland, 2002).

Several studies have concentrated on RVs in university undergraduate students' writing. Lee, Hitchcock and Casal (2018) explored research papers written by university 1 styear L2 learners. The findings indicated a restricted use of reporting citations and adopting a non-committal stance rather than a strong positive or negative position towards a cited material. Similarly, Liardét and Black (2019) have found that L2 learners majoring in predominantly soft domain disciplines rely on merely acknowledging structures such as state or according to in their university assignments, providing thus no subjective stance on the reported source. Analysing a corpus of 80,000 words from essays written by non-native undergraduates of two university departments of media studies and education, Ramoroka (2014) concludes that soft domain students use informative RVs neutral in passing the information from the source to the reader rather than interpreting the information cited. Similar results emphasising students' negligence to employ RVs in their variety were obtained by Manan and Noor (2015), who examined the use of RVs in undergraduate Master's theses by L2 learners majoring in English studies. According to Jomaa and Bidin (2016, 2017, 2019), who explored postgraduate students' theses, students depend on RVs to highlight ideas, attract readers' attention, affirm credibility to the cited information, or refer to the information. As Jomaa and Bidin (2019) argue, little information on the use of RVs in citation and students' native language interference may result in the need for more explicit instruction on the use of RV in the citation. The findings from both the hard and the soft domain thus indicate the necessity of raising students' awareness of using RVs in the citation at a postgraduate level (Jomaa and Bidin, 2019) and an undergraduate level (Manan and Noor, 2015; Nguyen and Pramoolsook, 2014, 2015, 2016; Samraj, 2013). 


\section{Aim and research questions}

The present paper aims to contribute to and shed more light on RVs' employment in undergraduate students' writing. Previous studies on RVs in undergraduate writing (Liardét and Black, 2019; Manan and Noor, 2014, 2015; Ramoroka, 2014) point to a relatively limited repertoire of RVs used in the citation. Unfortunately, most such research has been limited to one discipline or one disciplinary domain only (e.g. Lee, Hitchcock and Casal, 2018; Liardét and Black, 2019). However, research conducted on another genre - RAs - shows disciplinary differences in the use of RVs in the citation (e.g. Hyland and Jiang, 2017; Uba, 2020). We ask whether such differences in the use of RVs in citation can be traced in undergraduate writing.

Moreover, while studies performed on undergraduate writing mostly look at types and functions of RVs in the citation (e.g. Manan and Noor, 2014, 2015; Ramoroka, 2014), studies looking into the syntactic aspects such as the tense and voice of RVs used in reports are surprisingly missing. However, we believe that incorrect tense or voice choices in reporting structures might be challenging for L2 learners. We also raise the question of the subject-agent choice, which seems to be equally neglected. However, for L2 learners, the subject/verb agreement might easily present another conflicting issue. Together with RVs' vague or inappropriate choices, this may hinder students' academic writing quality.

This study thus set out to analyse the types of RVs and the underlying structures of the structures containing the RVs used in the theses written in English by L2, the students of two Master's programs, Economics and Management and Natural Resources, the former representing a "soft" and the latter "hard" discipline (Hyland, 1999). The investigation into the disciplinary differences in RVs usage may help us understand the choices student-writers make and may navigate us in improving the methodology of class instruction.

The study employed Hyland's (2002) categorisation framework enabling the division of RVs into categories according to the processes they describe. The classification further allows for a minute distinction of evaluative functions the RVs carry in each category, enabling the writer to position the reported claim or cited author. Thus, the study investigated only such reports which contained both the RV and the author expressed in the reporting structure (Swales, 1990).

The study sought to address the following research questions:

1. Which types and functions of RVs are used in Master's theses, and is the usage of RVs in the two disciplines different?

2. What verb tense and verb voice are used in the reports containing RVs?

3. How is the subject-agent expressed in the reports containing RVs?

\section{MATERIALS AND METHODS \\ Research design}

The research was performed on 164 Master's theses written in English by non-native speakers, students of two English programs studied at CULS Prague, Economics and Management and Natural Resources. The language of instruction in both programs is English. To be eligible to study the programs, students need to have an upper-intermediate to the advanced command of English, i.e. minimum at B2 level based on the Common European Framework for Languages. The created corpus contained 164 Literature Review sections from Master's theses that met the following criteria: 1) the theses were available online - to meet this criterion, only the theses no older than January 2016 could be considered, 2) were successfully defended between January 2016 and June 2020 at the time of performing this research no more recent theses were available, and 3) were written by non-native speakers - English L2 learners, which was verified by checking the students' bio-data available online. The corpus consisted of 164 texts and comprised 854,575 words in total, with each of the two sub-corpora having 82 texts. The Economics and Management (EM) sub-corpus contained 439,395 words in total, the length of individual texts varying from 3,899 to 6,401 words and amounting to 5,358 words per text on average. The Natural Resources (NR) sub-corpus contained 415,219 words in total, with the length of individual texts between 2,998 and 6,550 words and with 5,064 words per text on average. The texts in the sub-corpora were carefully read and searched for the occurrences of citations containing RVs.

The types of citations under analysis are illustrated in examples (1-3). Only such reporting structures were analysed where the name of the agent was specified either in the subject position - see example (1), or as a "by-adjunct" in the sentence structure - see example (2), or as a generalised or meta-linguistic expression used in place of the agent - see example (3). In the examples (1-3), both the RVs and the agent are italicised:

(1) "Clifford and Thorpe (2007) divide forms of selfdirected learning into three to four main categories." (EMLR6RV5);

(2) "It is also suggested by Becker and Armstrong (2002) that an organisation must anticipate and consecutively satisfy the employees' needs." (EMLR2RV2);

(3) "The study revealed that genetic factors influence job satisfaction by 30 per cent." (EMLR3RV5)

Each reporting structure was allocated a code - e.g. EMLR1RV1 - where LR1 stood for the Literature Review randomly coded from 1 to 82 and RV1 for the RV order in the particular section.

\section{Method of analysis}

Altogether 1,359 occurrences of RVs were extracted, 837 from the Economics and Management sub-corpus and 522 from the Natural Resources sub-corpus. The frequencies of individual RVs occurrences were counted. Frequencies are used to indicate how often a phenomenon occurs and are based on counting the number of occurrences (Seliger and Shohamy, 1990). Using descriptive statistics, we provided the frequencies of occurrences and the percentages of RVs identified in the corpus. We used a checklist to identify the RVs into categories and functions based on the indicators 
given by Hyland (2002). The checklist seemed to be the most suitable instrument as it guided us about the essential aspects or characteristics that should be focused on (Manan and Noor, 2014). To ensure the reliability and validity of the results, we consulted two independent coders during the data analysis.

The present study employed Hyland's (2002) framework of categorising RVs according to their evaluation of the RV's processes they describe or represent in the discourse, involving the writer's attitude to the reported context. After implementing the classification, the RVs' structures were analysed using verb characteristics, i.e., tense and voice. The tense is related to RVs' use, indicating how much the writer supports the cited author's claim (Swales, 1990).

In example (1), the writer uses the procedural research verb in the present tense (divide) to summarise the previous research. In contrast, in example (2), by using the tentative discourse verb in the passive (is suggested), the writer assumes the reader already knows what the cited authors found. In example (3), however, the use of the cognition verb in the past tense (revealed) implies the writer's opinion that the finding is new. Finally, the type and position of the sentence subject-agent were discussed. Since the paper aimed at the use of RVs and the related choice of the tense and voice, the cited author was understood as an "agent" or "doer" of the verbal activity expressed by the RV and positioned either as the subject in an active clause, as in example (1), or as the "by-adjunct" in a passive clause (2), with possibilities of other linguistic expressions further explored, e.g. as in example (3). Since in this analysis, the cited author is limited to two roles (Swales, 2014), i.e. the subject $(1,3)$ and the adjunct $(2)$, the further categorisation of the contextual roles (Jomaa and Bidin, 2016) was marginal.

\section{RESULTS}

\section{Types and functions of reporting verbs $\left(1^{\text {st }}\right.$ research question)}

The findings show a rather significant difference in the employment of RVs between the two sub-corpora. In economics and Management, 837 occurrences were recorded, averaging out to 10.21 occurrences per text; it was only 522 in Natural Resources, with a mean occurrence of 6.37 verbs per text (Table 1).

\begin{tabular}{c|c|c|c|c}
\multirow{2}{*}{ RVs } & \multicolumn{2}{|c|}{ Economics and Management } & \multicolumn{2}{c}{ Natural Resources } \\
\hline Occurrences in the & corpus & Mean occurrence per text & $\begin{array}{c}\text { Occurrences in the } \\
\text { corpus }\end{array}$ & Mean occurrence per text \\
\hline Discourse & $573(68.46 \%)$ & 6.99 & $183(35.06 \%)$ & 2.24 \\
\hline Research & $174(20.79 \%)$ & 2.12 & $336(64.37 \%)$ & 4.10 \\
\hline Cognition & $90(10.75 \%)$ & 1.10 & $3(0.57 \%)$ & 0.03 \\
\hline Total & $837(100 \%)$ & 10.21 & $522(100 \%)$ & 6.37 \\
\hline
\end{tabular}

Table 1: Frequencies of reporting verbs in the sub-corpora and their mean frequency per text

A minimal marginal occurrence was 0 (2 texts) in Economics and Management and 1 (3 texts) in Natural Resources, while the maximum marginal occurrence was 26 (1 text) in Economics and Management and 22 (1 text) in Natural Resources. In the sub-corpora, we can observe a contrary trend. In Economics and Management, the most highly represented were Discourse Acts verbs $(68.46 \%)$, followed by a significantly lower occurrence of Research Acts verbs $(20.79 \%)$ and even lower occurrence of Cognitive Acts verbs (10.75\%). The highest frequency of occurrences in Natural Resources can be attributed to Research Acts verbs (64.37\%), followed by Discourse Acts verbs $(35.06 \%)$. The frequency of Cognition Acts verbs is relatively insignificant, with only three occurrences $(0.03 \%)$.

As Table 2 illustrates, within Discourse Acts, the most highly represented category of RVs in Economics and Management, the Assurance verbs were by far the most frequent $(95.29 \%)$. The non-factive verbs $(56.55 \%)$, neutrally informing the reader of the author's position towards the cited material, were used more frequently than the factive verbs $(38.74 \%)$ employed by the writers to bolster their views and introduce the cited material in more positive or conclusive terms. In Natural Resources, the difference between non-factive $(59.02 \%)$ occurrences and factive $(8.19 \%)$ verbs was even more significant.
Although Counters, the final category of Discourse Acts verbs, referring to the author's reservations or objections to the correctness of the reported message, had no representatives in the Economics and Management subcorpus $(0 \%)$, in Natural Resources, the verb fail from Counters was recorded in three occurrences (1.64\%).

While in the Natural Resources sub-corpus, the difference in occurrences between Assurance (68.85\%) and Doubt $(31.15 \%)$ discourse verbs could be considered relatively moderate, in Economics and Management, the difference between Assurance (95.29\%) and Doubt (4.71\%) verbs was rather significant. All 27 occurrences in Economics and Management can be attributed to the tentative Doubt verb suggest $(4.71 \%)$. In Natural Resources, the occurrences can be attributed not only to suggest, which turned out to be the most frequented discourse verb in Natural Resource but also to tentative hypothesise and indicate, both recorded in lower frequencies (Table 3). The Doubt category verbs that are directly critical $(0 \%)$ were not used in either sub-corpus.

Research Acts verbs (Table 2) were by far the most frequent category in Natural Resources $(64.37 \%)$ as opposed to Economics and Management (20.79\%). However, in both disciplines, Procedure verbs considerably prevailed over Findings verbs, displaying higher frequency in Natural Resources (183) than in Economics and Management 
(108). Similarly, the Findings verbs were recorded in higher frequency (153) in the Natural Resources subcorpus than in Economics and Management (66), with factive verbs (111) significantly exceeding non-factive verbs (39). In contrast, in Economics and Management, the factive verbs' frequency (20.69\%) was slightly higher than that of the non-factive verbs $(17.24 \%)$.

Of the least represented Cognitive Acts verbs $(10.75 \%$ in Economics and Management and $0.57 \%$ in Natural Resources), it was the positive Cognitive Acts verbs $(70 \%)$ that occurred in abundance in the Economics and Management sub-corpus, mainly thanks to the 33 occurrences of agree representing the author as having a positive attitude to the reported material (Table 3 ). They were followed by the neutral verbs $(23.33 \%)$ representing the author as having a neutral attitude toward proposition and tentative verbs $(6.67 \%)$ represented by believe in 6 occurrences. Unlike in the Natural Resources sub-corpus, where believe was the only cognitive verb recorded in three occurrences only. Cognitive verbs presenting the author as taking a critical stance $(0 \%)$ toward the cited message were not found in either sub-corpus.

Table 3 displays the most commonly used RVs with the frequency of occurrences $\geq 5$ in the sub-corpora. It could be noted that Economics and Management students used Discourse Acts verbs in abundance and variety, whereas Natural Resources students' usage was scarcer.

In Economics and Management, the non-factive Discourse Acts verbs state and point out informing the readers neutrally of the authors' position were found in 75 and 69 occurrences each, amounting to $13.09 \% 12.04 \%$ of all Discourse Acts verbs (Table 3). The verb claim (10.99\%) supporting the reported information was the most frequent factive Assurance verb in 63 occurrences. Other most frequently used Discourse Acts verbs were non-factive Assurance verbs define in 57 occurrences (9.95\%), describe in 54 occurrences $(9.43 \%)$, and mention in 48 occurrences $(8.38 \%)$, followed by suggest in 27 occurrences $(4.71 \%)$. In Natural Resources, the tentative suggest in 48 occurrences $(26.23 \%)$ and the non-factive report in 45 occurrences $(24.59 \%)$ were the two most frequented discourse verbs followed by the non-tentative state in 15 occurrences only. Unlike Economics and Management students (20.79\%), Natural Resources students tended to use Research Acts verbs to report on the statement of findings or researchers' procedures much more frequently $(64.37 \%)$, with the most frequent factive Findings verb show (51 occurrences) followed by two most frequently used Procedures verbs conduct and carry out (each in 30 occurrences).

While in Natural Resources texts, the Cognitive Acts verbs recorded only one representative in three occurrences, believe $(0.57 \%)$, illustrating the author as having a tentative view of the reported matter, in Economics and Management, the use of cognitive verbs was slightly higher (10.57). The most frequent was agree in 33 occurrences (36.67\%), followed by think in 15 occurrences (16.67\%), both verbs representing authors as having a positive attitude.

We might argue that a "neutral" attitude also reflects a positive attitude toward the cited author as believe does. The uses do not seem to imply any difference. Consequently, it could be argued that all the verbs cited describe the tentative position of the author. These verbs allow the writer to take a critical stance, although they are not inherently critical.

\begin{tabular}{|c|c|c|c|c|}
\hline \multirow{2}{*}{$\begin{array}{l}\text { Category/ } \\
\text { Subcategory }\end{array}$} & \multicolumn{2}{|c|}{ Economics and Management } & \multicolumn{2}{|c|}{ Natural Resources } \\
\hline & Frequency & Percentage & Frequency & Percentage \\
\hline Research Acts & 174 & 20.79 & 336 & 64.37 \\
\hline Findings & 66 & 37.99 & 153 & 45.54 \\
\hline Factive & 36 & 20.69 & 111 & 33.04 \\
\hline Non-factive & 30 & 17.24 & 39 & 11.61 \\
\hline Counter-factive & 0 & 0.00 & 3 & 0.89 \\
\hline Procedures & 108 & 62.07 & 183 & 54.46 \\
\hline Cognitive Acts & 90 & 10.75 & 3 & 0.57 \\
\hline Positive & 63 & 70.00 & 0 & 0.00 \\
\hline Critical & 0 & 0.00 & 0 & 0.00 \\
\hline Tentative & 6 & 6.67 & 3 & 0.57 \\
\hline Neutral & 21 & 23.33 & 0 & 0.00 \\
\hline Discourse Acts & 573 & 68.46 & 183 & 35.06 \\
\hline Doubt & 27 & 4.71 & 57 & 31.15 \\
\hline Tentative & 27 & 4.71 & 57 & 31.15 \\
\hline Critical & 0 & 0.00 & 0 & 0.00 \\
\hline Assurance & 546 & 95.29 & 126 & 68.85 \\
\hline Factive & 222 & 38.74 & 15 & 8.19 \\
\hline Non-factive & 324 & 56.55 & 108 & 59.02 \\
\hline Counters & 0 & 0.00 & 3 & 1.64 \\
\hline Total & 837 & 100 & 522 & 100 \\
\hline
\end{tabular}

Table 2: Frequencies of reporting verbs in different evaluative functions in the discourse 


\begin{tabular}{|c|c|c|c|c|c|}
\hline \multicolumn{3}{|c|}{ Economics and Management } & \multicolumn{3}{|c|}{ Natural Resources } \\
\hline Category / RV & Frequency & Percentage & Category / RV & Frequency & Percentage \\
\hline Discourse Acts & 573 & 68.46 & Discourse Acts & 183 & 35.06 \\
\hline state & 75 & 13.09 & suggest & 48 & 26.23 \\
\hline point out & 69 & 12.04 & report & 45 & 24.59 \\
\hline claim & 63 & 10.99 & state & 15 & 8.19 \\
\hline define & 57 & 9.95 & propose & 9 & 4.92 \\
\hline describe & 54 & 9.43 & argue & 8 & 4.37 \\
\hline mention & 48 & 8.38 & define & 7 & 3.83 \\
\hline suggest & 27 & 4.71 & highlight & 6 & 3.28 \\
\hline argue & 15 & 2.62 & indicate & 6 & 3.28 \\
\hline stress & 15 & 2.62 & mention & 6 & 3.28 \\
\hline highlight & 15 & 2.62 & say & 6 & 3.28 \\
\hline say & 13 & 2.27 & $R V s \leq 5$ & 27 & 14.75 \\
\hline conclude & 12 & 2.09 & & & \\
\hline introduce & 11 & 1.92 & & & \\
\hline predefine & 9 & 1.57 & & & \\
\hline emphasise & 8 & 1.39 & & & \\
\hline$R V s \leq 5$ & 82 & 14.31 & & & \\
\hline Research Acts & 174 & 20.79 & Research Acts & 336 & 64.37 \\
\hline add & 51 & 29.31 & show & 51 & 15.19 \\
\hline examine & 12 & 6.89 & conduct & 30 & 8.93 \\
\hline recommend & 10 & 5.75 & carry out & 30 & 8.93 \\
\hline observe & 10 & 5.75 & study & 24 & 7.14 \\
\hline compare & 9 & 5.17 & find & 15 & 4.46 \\
\hline conduct & 9 & 5.17 & develop & 15 & 4.46 \\
\hline find & 8 & 4.60 & analyse & 13 & 3.87 \\
\hline confirm & 6 & 3.45 & confirm & 12 & 3.57 \\
\hline divide & 6 & 3.45 & use & 12 & 3.57 \\
\hline explore & 6 & 3.45 & demonstrate & 10 & 2.98 \\
\hline display & 6 & 3.45 & establish & 9 & 2.67 \\
\hline \multirow[t]{6}{*}{$R V s \leq 5$} & 41 & 23.56 & evaluate & 8 & 2.37 \\
\hline & & & achieve & 6 & 1.79 \\
\hline & & & observe & 6 & 1.79 \\
\hline & & & present & 6 & 1.79 \\
\hline & & & indicate & 5 & 1.49 \\
\hline & & & $R V s \leq 5$ & 84 & 25.00 \\
\hline Cognition Acts & 90 & 10.75 & Cognition Acts & 3 & 0.57 \\
\hline agree & 33 & 36.67 & believe & 3 & 0.57 \\
\hline think & 15 & 16.67 & & & \\
\hline reveal & 12 & 13.33 & & & \\
\hline perceive & 9 & 10.00 & & & \\
\hline believe & 6 & 6.66 & & & \\
\hline$R V s \leq 5$ & 15 & 16.67 & & & \\
\hline Total & 837 & 100 & Total & 522 & 100 \\
\hline
\end{tabular}

Table 3: Most common reporting verbs with occurrences $\leq 5$

The verb tense and voice in reporting structures containing reporting verbs ( $2^{\text {nd }}$ research question)

In Economics and Management texts, the student-writers preferred the present active $(78.85 \%)$, followed by considerably lower use of the past active (13.98\%) and even less effective use of present perfect active. In Natural Resources, it was the past active $(64.37 \%)$ that significantly dominated over the present active $(8.62 \%)$ and the present perfect active (2.30\%). Table 4 illustrates the distribution of the overall use of tense and voice forms found in RVs' structures across the sub-corpora.
As regards the passive forms, they were much more frequently used by the students of Natural Resources. The most frequent was the past passive $(20.12 \%)$, which was thus the second primary choice after the active forms in the past tense (64.37), followed by the present passive $(2.87 \%)$ and the present perfect passive $(1.72 \%)$. In reporting structures from Economics and Management, the passive voice was used only in the present $(4.30 \%)$ and past tense $(1.08 \%)$.

Table 5 and Table 6 present the tense and voice forms in correlation with RVs categories used in the sub-corpora. 


\begin{tabular}{l|c|c|c|c}
\multirow{2}{*}{ Tense and Voice } & \multicolumn{2}{c|}{ Economics and Management } & \multicolumn{2}{c}{ Natural Resources } \\
\cline { 2 - 5 } & Frequency & Percentage & Frequency & Percentage \\
\hline Present active & 660 & 78.85 & 45 & 8.62 \\
\hline Present passive & 36 & 4.30 & 15 & 2.87 \\
\hline Present perfect active & 15 & 1.79 & 12 & 2.30 \\
\hline Present perfect passive & 0 & 0.00 & 9 & 1.72 \\
\hline Past active & 117 & 13.98 & 336 & 64.37 \\
\hline Past passive & 9 & 1.08 & 105 & 20.12 \\
\hline Total & $\mathbf{8 3 7}$ & $\mathbf{1 0 0 \%}$ & $\mathbf{5 2 2}$ & $\mathbf{1 0 0 \%}$ \\
\hline
\end{tabular}

Table 4: Tense and voice in reporting structures with reporting verbs

\begin{tabular}{l|cc|cc|cr}
\hline \multicolumn{1}{c}{ Verb tense and voice } & \multicolumn{2}{c}{ Research Acts } & \multicolumn{2}{c}{ Discourse Acts } & \multicolumn{2}{c}{ Cognitive Acts } \\
\hline Present active & 123 & $70.69 \%$ & 450 & $78.54 \%$ & 87 & $96.67 \%$ \\
\hline Present passive & 0 & $0.00 \%$ & 36 & $6.28 \%$ & 0 & $0.00 \%$ \\
\hline Present perfect active & 6 & $3.45 \%$ & 9 & $1.57 \%$ & 0 & $0.00 \%$ \\
\hline Present perfect passive & 0 & $0.00 \%$ & 0 & $0.00 \%$ & 0 & $0.00 \%$ \\
\hline Past active & 45 & $25.86 \%$ & 69 & $12.04 \%$ & 3 & $3.33 \%$ \\
\hline Past passive & 0 & $0.00 \%$ & 9 & $1.57 \%$ & 0 & $0.00 \%$ \\
\hline Total & $\mathbf{1 7 4}$ & $\mathbf{1 0 0 \%}$ & $\mathbf{5 7 3}$ & $\mathbf{1 0 0 \%}$ & $\mathbf{9 0}$ & $\mathbf{1 0 0 \%}$ \\
\hline
\end{tabular}

Table 5: Tense and voice choices in correlation with reporting verbs' categories in Economics and Management

\begin{tabular}{l|cc|cc|cc}
\hline \multicolumn{1}{c}{ Verb tense and voice } & \multicolumn{2}{c}{ Research Acts } & \multicolumn{2}{c}{ Discourse Acts } & \multicolumn{2}{c}{ Cognitive Acts } \\
\hline Present active & 15 & $4.46 \%$ & 30 & $16.39 \%$ & 0 & $0 \%$ \\
\hline Present passive & 6 & $1.79 \%$ & 6 & $3.28 \%$ & 3 & $20 \%$ \\
\hline Present perfect active & 12 & $3.57 \%$ & 0 & $0.00 \%$ & 0 & $0 \%$ \\
\hline Present perfect passive & 3 & $0.89 \%$ & 6 & $3.28 \%$ & 0 & $0 \%$ \\
\hline Past active & 231 & $68.75 \%$ & 105 & $57.38 \%$ & 0 & $0 \%$ \\
\hline Past passive & 69 & $20.54 \%$ & 36 & $19.67 \%$ & 0 & $0 \%$ \\
\hline Total & $\mathbf{3 3 6}$ & $\mathbf{1 0 0 \%}$ & $\mathbf{1 8 3}$ & $\mathbf{1 0 0 \%}$ & $\mathbf{3}$ & $\mathbf{1 0 0 \%}$ \\
\hline
\end{tabular}

Table 6: Tense and voice choices in correlation with reporting verbs' categories in Natural Resources

In Economics and Management (Table 5), where the most frequent RVs category were Discourse Acts, the primary choice was the present active accounting for $78.54 \%$ of Discourse Acts verbs. However, the present active was the prevalent choice in Research Acts (70.69\%) and cognitive act verbs (96.67\%).

The present tense can be used with verbs of communication to make a generalisation as in example (4) and imply that the information communicated as the result of past communication is still operative, as in example (5). Both are illustrated on a tentative discourse verb suggest:

(4) "Yao et al. (2013) suggest that BC can play a role in the retention of $\mathrm{P}$ applied in fertilisers." (NRLR3RV4)

(5) "Denton (1998) suggests that naturally it depends on the size and resources given, whether the organisation seeks for some kind of assistance." (EMLR20RV2)

With Discourse Acts verbs, which linguistically express reported findings, procedures and mental processes, the writers opted for the present tense forms to emphasise the significance of the reported messages to their studies. Thus, the present active was a predominant choice for Discourse Acts verbs in the Natural Resources sub-corpus (16.39\%) instead of only $4.46 \%$ of Research Acts verbs in the present tense (Table 6).

The primary tense choice for Natural Resources texts, where Research Acts verbs were predominant, was the past active, the most frequently used tense for Research Acts (57.38\%) and Discourse Acts verbs (68.75\%). Its use implies a greater distancing of the writer from another author's reported message and less relevance to the writer's research, as is illustrated by a non-factive discourse verb summarised in example (6). Alternatively, as in example (7), the procedural Research Acts verb describes a past process with significance to a current study:

(6) "Dolinar et al. (2007) summarised relationship between clay mineralogy and Atterberg's limits.” (NRLR50RV3)

(7) "Bart Victor and John B. Cullen (1988) discovered a typology of ethical climate." (EMLR23RV2)

Similarly, the use of past tenses may reflect the dating of the research, not necessarily the relationship of the writer to the cited author, i.e. the reported message might be older but not less relevant. Thus, also the Economics and Management writers (Table 5) used the past tense forms for Research Acts verbs in a higher percentage $(25.9 \%)$ than for Discourse Acts verbs (12.0\%) or Cognitive Acts verbs (3.3\%).

A higher percentage of the present perfect active forms in Economics and Management (Table 5) were recorded for the Research Acts verbs (3.45\%) than for the Discourse Acts verbs (1.57\%). In Natural Resources, the present perfect active was used with Research Acts verbs only (3.57\%), setting up 
a current situation that was created by previously reported research, as illustrated by a research verb show in example (8):

(8) "Research has shown that only genes coding GCPII are present in trematodes and nematodes." (NRLR10RV2)

Since "research" is a collective noun, it indicates a proper use of the present perfect reflecting a summary of research supporting the relevance of the writer's write-up. Such a tendency to review a group of research summarised using the present perfect was more profound in the texts by Natural Resources writers.

Although most RVs in both sub-corpora were used in active forms, several Discourse Acts verbs in Economics and Management (Table 5) occurred in the present passive $(6.28 \%)$ and the past passive (1.57\%). In Natural Resources (Table 6), the use of passive forms was considerably more significant as the passive forms occurred in structures with RVs from all three categories in both the present and the past tense. Although the past passive predominated in Research Acts (20.54\%) and Discourse Acts (19.67\%) over the present passive (1.79\% Research Acts and 3.28\% Discourse Acts), the three occurrences of believe, the only Cognitive Acts verb in the sub-corpus, were in the present passive:
(9) "It is believed by Oldeman (1991) that the value underestimates the real degree of pollution." (NRLR23RV2)

\section{The subject-agent in citations containing reporting verbs ( $3^{\text {rd }}$ research question)}

In both sub-corpora, in most structures, the subject-agent was expressed as a named-author. While in Economics and Management (Table 7), a single-named author (e.g. "Denton (1998) suggests...") exceedingly prevailed over a multiplenamed author, in Natural Resources (Table 8), it was a multiple-named author as subject (e.g. "Dolinar et al. (2007) summarised...") that was predominant. While in Economics and Management, we can also observe a pronominal subject in place of a single-named author; in Natural Resources, no pronominal replacement was recorded.

Although subject-agent expressed by other means than the name(s) of the author(s) (e.g. "The study revealed...", "Research has shown...") was much less frequent in both sub-corpora, in Natural Resources the frequency of use was more significant than in Economics and Management. In all passive forms under analysis, the agent-author was expressed as a by-adjunct (e.g. "...is believed by Oldeman (1991)...", “...is suggested by Becker and Armstrong (2002)...").

\begin{tabular}{l|cc|cc|cc}
\hline \multicolumn{1}{c}{ Tense/Subject-agent } & \multicolumn{2}{c}{ Present Active } & \multicolumn{2}{c}{ Past Active } & \multicolumn{2}{c}{ Present Perfect Active } \\
\hline Named author & 630 & $95.45 \%$ & 99 & $84.62 \%$ & 9 & $60 \%$ \\
\hline Single-named author & 480 & $76.19 \%$ & 63 & $63.64 \%$ & 0 & $0 \%$ \\
\hline Pronominal (he, she) & 42 & $6.67 \%$ & 6 & $6.06 \%$ & 0 & $0 \%$ \\
\hline Multiple-named author & 108 & $17.14 \%$ & 21 & $21.21 \%$ & 9 & $100 \%$ \\
\hline Pronominal (they) & 0 & $0.00 \%$ & 9 & $9.09 \%$ & 0 & $0 \%$ \\
\hline Meta-text term & 30 & $4.55 \%$ & 18 & $15.38 \%$ & 6 & $40 \%$ \\
\hline Total & $\mathbf{6 6 0}$ & $\mathbf{1 0 0 \%}$ & $\mathbf{1 1 7}$ & $\mathbf{1 0 0 \%}$ & $\mathbf{1 5}$ & $\mathbf{1 0 0 \%}$ \\
\hline
\end{tabular}

Table 7: Subject-agent in correlation with tense choice in Economics and Management

\begin{tabular}{l|cc|cc|cc}
\multicolumn{1}{c}{ Tense/Subject-agent } & \multicolumn{2}{c}{ Present Active } & \multicolumn{2}{c}{ Past Active } & \multicolumn{2}{c}{ Present Perfect Active } \\
\hline Named author & 27 & $60 \%$ & 276 & $82.14 \%$ & 0 & $0 \%$ \\
\hline Single-named author & 0 & $0 \%$ & 12 & $4.35 \%$ & 0 & $0 \%$ \\
\hline Pronominal (he, she) & 0 & $0 \%$ & 0 & $0.00 \%$ & 0 & $0 \%$ \\
\hline Multiple-named author & 27 & $100 \%$ & 258 & $93.48 \%$ & 0 & $0 \%$ \\
\hline Pronominal (they) & 0 & $0 \%$ & 6 & $2.17 \%$ & 0 & $0 \%$ \\
\hline Meta-text term & 18 & $40 \%$ & 60 & $17.86 \%$ & 12 & $100 \%$ \\
\hline Total & $\mathbf{4 5}$ & $\mathbf{1 0 0 \%}$ & $\mathbf{3 3 6}$ & $\mathbf{1 0 0 \%}$ & $\mathbf{1 2}$ & $\mathbf{1 0 0 \%}$ \\
\hline
\end{tabular}

Table 8: Subject-agent in correlation with tense choice in Natural Resource

\section{Summary of the results}

It could be argued that the number of occurrences could not guarantee the frequency of the actual use of the verbs. However, we can observe the consistency of our results with other research, which showed variations. Studies confirmed the predominance of RVs in soft disciplines as opposed to hard domains (Hyland and Jiang, 2017; Uba, 2020). In soft fields, discourse verbs tend to predominate not only in the writing of inexperienced (Lee, Hitchcock and Casal, 2018; Liardét and Black, 2019; Ramoroka, 2014) or non-native writers
(Jafarigohar and Mohammadkhani, 2015), but they seem to be a superior choice also for native speakers (Hyland, 1998; 1999). Our findings suggest similar disciplinary variations. The number of RVs occurrences in the Natural Resources was strikingly lower than the number of occurrences in the Economics and Management sub-corpus. The vast majority of the occurrences of the RVs in Economics and Management were non-factive Assurance Discourse verbs, while in Natural Resources, it was Procedures Research Acts verbs. Procedures verbs also dominated among less frequent Research Acts in 
Economics and Management. Similarly, non-factive Assurance verbs were more frequent among much less used Discourse Acts verbs in Natural Resources.

Cognitive Acts verbs, positive and neutral, occurred scarcely in Economics and Management and were nearly lacking in Natural Resources. Occurrences of RVs in other critical evaluative functions were, except for one occurrence in Natural Resources, virtually non-existent.

Research reports present active forms as dominant in native speakers' soft domain writing (Swales and Feak, 2004). In both sub-corpora, most RVs occurred in active forms. The findings thus do not suggest overuse of the passive. However, in some instances, they might point to inappropriate, if not incorrect use, as shown in example (2) on a tentative discourse verb suggest and neutral cognitive verb believe (9). The majority of discourse verbs in the Economics and Management subcorpus were in the present active. Although it may seem that the Economics and Management students-writers used the past tense in a higher number of occurrences of Research Acts verbs rather than Discourse Acts, the present tense remains to be the significant tense choice in the sub-corpus. In Natural Resources, it was the past active used in most structures with Research Acts verbs. Despite being predominant, the past tense was not the foremost choice for Discourse Acts verbs, where the present tense was preferred. However, the results from Economics and Management seem to suggest the overuse of the present tense. When reporting on older sources dated in the past, the present tense might no longer feel appropriate, cf. example (5). The present perfect was used relatively infrequently in either sub-corpus, with a moderately higher frequency of Research Acts verbs in the present perfect in Natural Resources.

Research suggests the dominance of the cited author as the sentence subject in active clauses followed by the cited author as the by-adjunct in passive clauses (Swales, 2014). In the subcorpora, in the vast majority of citations, the cited author was the sentence subject. Expressions other than the name of the cited author's name were used less. However, they seemed to prevail in Natural Resources, where they were increasingly used with research verbs in the present perfect.

\section{DISCUSSION}

This study explored RVs' use in the Literature Review sections of Master's theses written in English by L2 learners, the students of two disciplines, Economics and Management and Natural Resources. The research addressed three research questions regarding the 1) categories and functions of the RVs and differences between the two disciplines, 2) tense and voice of the RVs, and 3) subject-agent in the structures with RVs.

As for the $1^{\text {st }}$ research question, the research, conducted on 82 texts from each sub-corpus, revealed a much higher tendency to use RVs by Economics and Management students (873 occurrences of RVs) than by Natural Resources students (522 occurrences). This finding corroborates previous studies' results (Hyland, 1999; Hyland and Jiang, 2017; Uba, 2020) that there are variations in frequency in using RVs across disciplines. This may suggest that the student-writers of Economics and Management, categorised as arts and humanities or the so- called soft science, use RVs in higher frequency than those of Natural Resources, which is natural science or hard discipline. As Uba (2020) argues, a higher frequency of RVs in soft disciplines might result from the disciplinary discourse, where there is a need for more subjectivity than in hard disciplines, where writers tend to use a more objective stance. True to this, our findings revealed a predominant use of Research Acts verbs in Natural Resources texts, describing procedures or processes performed in previous studies or introducing results or conclusions of the previous research.

In contrast, our results suggest a predominant use of neutral Discourse Acts verbs in Economics and Management texts, where they merely acknowledge reported communication without expressing a more profound or even critical stance. However, neutral discourse verbs were predominant even in Natural Resources texts, where a more subjective stance towards the reported material was nearly lacking. This is again in line with Uba (2020), whose findings suggest a higher use of neutral RVs in hard and soft disciplines. Many studies confirm the use of neutral discourse verbs in various genres, for example, Ramoroka (2014), Lee, Hitchcock and Casal (2018) or Liardét and Black (2019) in undergraduates' papers, Mansourizadeh and Ahmad (2011), Agbaglo (2017) or Hyland and Jiang (2017) in RAs.

As for the $2^{\text {nd }}$ research question, in most structures with RVs under analysis, the active forms prevailed over the passive forms. While Economics and Management students used the present tense exceedingly not only with discourse verbs but also with other two less frequent categories, research and cognitive verbs, in Natural Resources texts, it was the past tense that dominated not only in structures with the most frequently used research verbs but also with less frequently used discourse verbs. The hard discipline student-writers used the past tense predominantly when reporting on past singular studies, which is justifiable as the Research Acts denote procedures of what the cited author "did" rather than what the cited author "says". Thus, our findings are consistent with Swales and Feak (2004) and Hawes and Thomas (1997), who state that the past tense refers to single studies. The soft discipline students' preference for the present tense might again not be surprising. As Swales and Feak (2004) indicate, this tense is the most dominant in the introduction or literature review sections of RAs. Thus, it seems to be the case that our students' citation practices are not very different from other social science writers in whose writing the use of discourse verbs in the present tense is the most prominent. In the study by Hawes and Thomas (1997), however, the use of the present perfect in the passive voice predominated over the other two tenses, with both the past and the present perfect in the active voice occurring much more frequently than the present tense. While in our study, the use of the present perfect was relatively infrequent. Such contrary findings may well be attributed to different sizes of the corpora and material analysed. The infrequent use of the present perfect forms in the present-study analysis may, according to Hawes and Thomas (1997), also suggest the student-writer's lower ability to provide particulars for a preceding generalisation or the basis for a claim or highlight the direct relevance of the previous studies to their research. Given the generally 
infrequent use of the present perfect in academic writing, the finding is not surprising.

As for the $3^{\text {rd }}$ research question, the student-writers in both disciplines extensively used the cited author's name rather than other expressions referring to the cited work (e.g. the study, research). This finding is in line with Swales (2014), in whose analysis of citation types the cited author was predominant as the sentence subject in active clauses, followed by the agent's function in the passive clause. In line with Swales (2014), our citations show a lower percentage of the cited author in an agent's function, i.e. a "by-adjunct" used with the passive verb. Jomaa and Bidin (2016) assign the cited author a prominent role, especially in soft domains of science, based on arguments rather than action. Hence, the preference for the cited author in the function of the subject integrated with the structure of the clause and, based on argumentative verbal processes, having the role of the "Sayer". Thus, in our study, following the Functional Theory approach and in line with Swales (2014) and Jomaa and Bidin (2016), under the interpersonal meanings, the cited author dominated in the subject's role in active over the adjunct role in passive clauses. The role of the cited author as the subject conflated to a significant extent with the functional role of the cited author as the "Sayer" (in citations with discourse verbs), followed by "Actor" (with research verbs) and "Senser" (with cognitive verbs). The cited author as the adjunct conflated with the role of the "Agent", preceded by the preposition "by" as a "by-adjunct" (Hawes and Thomas, 1997) in clauses with RVs in the passive voice.

Hawes and Thomas (1997) argued that the present tense verbs with named researcher as the subject were always discourse verbs and never non-discourse verbs in the medical journals researched. Past tense verbs with the named researcher as the subject were from both categories. A similar tendency could be observed in Natural Resources texts with a preference for research verbs in the past tense and the named author as the subject but not in Economics and Management, where the present tense was predominant in discourse and non-discourse verbs.

Our findings indicate that the disciplinary differences in the use of RVs in citation frequently reported in the genre of scientific articles (Agbaglo, 2017; Jafarigohar and Mohammadkhani, 2015; Mansourizadeh and Ahmad, 2011) such as lower incidence of RVs in hard disciplines or a preference of neutral discourse RVs in soft domains, may as well be attributed to the writing of undergraduate students. In hard discipline, the student-writers described the processes the cited authors "did", which explains the higher use of research verbs as opposed to a soft discipline, where the student-writers commented on what the cited authors "said". However, in both disciplines, the student writers were disinclined to show a more defined stance toward the cited messages. The disciplinary variations could be caused by different genres cited or by the number of cited materials. Such findings would impact the results on the use of RVs across disciplines, and it would therefore be beneficial to examine citations from this perspective.

We believe that it is still important to emphasise different RV types and make student-writers aware of the variety at their disposal when synthesising other authors' findings and taking a stance towards a cited message. L2 learners should be mindful of their choices regarding tense usage in citation structures, and their practice should not miss on English academic writing courses curricula. We agree with Nguyen and Pramoolsook $(2015,2016)$, who suggest that a clear focus on the lexical, grammatical aspects of citation in terms of accurate structures and appropriately used RVs should be introduced into the academic writing classroom. As Jomaa and Bidin (2019) suggest, involving the information on citation and different RVs in academic writing textbooks and authentic materials from students and experts' writings would benefit novice writers. We believe in line with Jomaa and Bidin (2019) that combining students' academic practices with understanding academic texts in context is essential for applying the findings into academic writing courses at undergraduate or postgraduate levels.

This research did not aim to change university course syllabi but to establish a proper approach to teaching methodology of RVs in the citation in academic writing courses. As the results imply, the student-writers of undergraduate theses did not significantly differ from other, more expert writers of other genres - in particular RAs. However, a broader awareness of the RVs' repertoire with all their minute distinctions to convey the cited message as closely as possible and paraphrase it to reflect the writer's own stance might benefit them. Conducting our research on Master's theses has allowed us to learn more about academic language in use and students' common errors when using academic English, especially in lexicon and grammar. Grammar is of particular importance in both scholarly written and spoken communication. The examined material comprises RVs that are used in a wide variety of topics in academic contexts. Based on the results, teachers could increasingly concentrate on practising RVs in various discourse functions. We hope that enhancing RVs' issues in academic writing courses will help students succeed in their academic studies in English and write RAs in English.

We are aware of the limitations of this study. The research was limited to the structures containing both the RV and the expressed subject-agent only. The findings were further limited to RVs' types, functions, and characteristics in citations of Master's thesis Literature Review sections of two disciplines. The study did not employ, e.g. discourse-based interviews to support the qualitative approach to the analysis (Hyland, 2012; Jomaa and Bidin, 2019), nor did it make use of, e.g. a movebased analysis (Nguyen and Pramoolsook, 2014), applicable within the genre-based approach (Hyland, 2004; Petrić, 2007; Swales, 1990) to research on academic writing (Hyland 2012, 2014). These descriptive research results are still built on sound evidence of how English is used by Master's students - non-native speakers - in their theses. Thus, as we believe, the study may be considered a sample representation of how citations, and RVs in particular, are used in academic writing by undergraduate L2 learners. The comparison with postgraduate students' final theses in this field of research could be performed to determine how successfully implementing the citation to academic writing syllabi has proven and whether or not there has been any significant progress in proper citation usage upon the implementation. 


\section{CONCLUSION}

The paper investigated the use of RVs in L2 learners' writing. It did so on two sub-corpora of Literature Reviews of Master's theses written in English by non-native speakers, Economics and Management and Natural Resources students. The findings reported differences in frequencies, types, and functions of the $\mathrm{RVs}$ used in the two disciplines. In the former, soft discipline, we could observe high use of neutral discourse verbs in the present active with the named-author as the subject, communicating generalised interpretations or conclusions. However, the students showed a slight preference for the past tense verb forms, providing a basis for a claim or particulars for preceding generalisation. In the latter, hard discipline, RVs were recorded in a lower frequency, with predominating research verbs in the past tense with the named-author as the subject, commenting on procedures or findings. Verbs signifying various evaluative roles were not as frequent in either discipline. The present perfect forms' deployment to highlight the previous research's relevance to the writer's write-up was even less significant.

Promoting various RVs carrying a more pronounced citation stance is still of great importance in L2 learners' academic writing courses. As a practical benefit of this study, the findings might help adjust syllabi of academic English courses at institutions where English is a non-native language, enhancing students' understanding of academic writing elements and RVs in citation structures in particular. Performing broader experimental research might contribute to evidence on academic writing knowledge's effectiveness at a tertiary education level.

\section{REFERENCES}

Agbaglo, E. (2017) 'The Types and the Frequencies of Reporting Verbs in Research Articles Written by Lecturers in a Ghanaian University', Journal of Literature, Language and Linguistics, Vol. 34, pp. 51-57.

Bloch, J. (2010) 'A concordance-based study of the use of reporting verbs as rhetorical devices in academic papers', Journal of Writing Research, Vol. 2, No. 2, pp. 219-244. https://doi.org/10.17239/jowr$\underline{2010.02 .02 .7}$

Harwood, N. (2009) 'An interview-based study of functions of citations in academic writing across two disciplines', Journal of Pragmatics, Vol. 41, No. 3, pp. 497-518. https://doi.org/10.1016/j. pragma.2008.06.001

Hawes, T. and Thomas S. (1997) 'Tense Choices in Citations', Research in the Teaching of English, Vol. 31, No. 3, pp. 393-414.

Hyland, K. (1998) Hedging in scientific research articles. Amsterdam: John Benjamins.

Hyland, K. (1999) 'Academic attribution: Citation and the construction of disciplinary knowledge', Applied Linguistics, Vol. 20, No. 3, pp. 341-367. https://doi.org/10.1093/applin/20.3.341

Hyland, K. (2002) 'Activity and evaluation: reporting practices in academic writing', in Flowerdew, J. (ed.), Academic discourse, London: Longman, pp. 115-130.

Hyland, K. (2004) Disciplinary Discourses. Ann Arbor: University of Michigan.

Hyland, K. (2012) 'English for Academic Purposes and Discourse Analysis', in Gee, J. P. and Handford, M. (ed.), Routledge Handbook of Discourse Analysis, London: Routledge, pp. 412-423.

Hyland, K. (2014) 'English for Academic Purposes', in Leung, C. and Street, B. (ed.) The Routledge Companion to English Studies, London: Routledge.

Hyland, K. and Jiang, F. K. (2017) 'Is academic writing becoming more informal?', English for Specific Purposes, Vol. 45, pp. 40-51. https:// doi.org/10.1016/j.esp.2016.09.001

Jafarigohar, M. and Mohammadkani, A. (2015) 'Reporting verbs in applied linguistics research articles by native and non-native writers', Theory and Practice in Language Studies, Vol. 5, No. 12, pp. 2490-2496. https://doi.org/10.17507/tpls.0512.08

Jomaa, N. J. and Bidin, S. J. (2016) 'Roles of the cited author in citations of the literature review by EFL postgraduates', International Journal of Applied Linguistics and English Literature, Vol. 5, No. 7, pp. 213225. https://doi.org/10.7575/aiac.ijalel.v.5n.7p.213
Jomaa, N. J. and Bidin, S. J. (2017) 'Perspective of EFL doctoral students on challenges of citations in academic writing', Malaysian Journal of Learning and Instruction, Vol. 14, No. 2, pp. 177-209. https://doi. org/10.32890/mjli2017.14.2.7

Jomaa, N. J. and Bidin, S. J. (2019) 'Variations in the Citation Use and Perceptions in Writing the Literature Review by EFL Postgraduates', Eurasian Journal of Applied Linguistics, Vol. 5, No. 3, pp. 441-460. http://dx.doi.org/10.32601/ejal.651398

Lee, J. L., Hitchcock, C. and Casal, J. E. (2018) 'Citation practices of L2 university students in first-year writing: Form, function, and stance', Journal of English for Academic Purposes, Vol. 33, pp. 1-11. https:// doi.org/10.1016/j.jeap.2018.01.001

Liardét, C. L. and Black, S. (2019) "'So and so" says, states and argues: A corpus-assisted engagement analysis of RVs', Journal of Second Language Writing, Vol. 44, pp. 37-50. https://doi.org/10.1016/j. jslw.2019.02.001

Manan, N. A. and Noor, N. M. (2014) 'Analysis of RVs in Master's theses', Procedia - Social and Behavioural Sciences, Vol. 134, pp. 140-145. https://doi.org/10.1016/j.sbspro.2014.04.232

Manan, N. A. and Noor, N. M. (2015) 'The use of integral citations in Master's degree theses', International Journal of Education and Research, Vol. 3, No. 7, pp. 233-246.

Mansourizadeh, K. and Ahmad, U. K. (2011) 'Citation practices among non-native expert and novice scientific writers', Journal of English for Academic Purposes, Vol. 10, No. 3, pp. 152-161. https://doi. org/10.1016/j.jeap.2011.03.004

Nguyen, T. T. L. and Pramoolsook, I. (2014) 'A move-based structure of the master's thesis literature review chapters by Vietnamese TESOL postgraduates', LangLit: An International Peer-Reviewed Open Access Journal, Vol. 1, No. 2, pp. 283-301.

Nguyen, T. T. L. and Pramoolsook, I. (2015) 'Citation in Vietnamese TESOL: Analysis of master's thesis introduction chapters', The Asian ESP Journal, Vol. 2, No. 1, pp. 95-118.

Nguyen, T. T. L. and Pramoolsook, I. (2016) 'Citations in literature review chapters of TESOL master's theses by Vietnamese postgraduates', GEMA Online Journal of Language Studies, Vol. 16, No. 2, pp. 17-32. https://doi.org/10.17576/gema-2016-1602-02

Petrić, B. (2007) 'Rhetorical functions of citations in high- and low-rated Master's theses', Journal of English for Academic Purposes, Vol. 6, No. 3, pp. 238-253. https://doi.org/10.1016/j. jeap.2007.09.002 
Petrić, B. and Harwood, N. (2013) 'Task requirements, task representation, and self-reported citation functions: An exploratory study of a successful L2 student's writing', Journal of English for Academic Purposes, Vol. 12, No. 2, pp. 110-124. https://doi. org/10.1016/j.jeap.2013.01.002

Ramoroka, B. T. (2014) 'Integration of sources in academic writing: a corpus-based study of citation practices in essay writing in two departments at the University of Botswana', Reading and Writing, Vol. 5, No. 1, pp. 1-7. https://doi.org/10.4102/rw.v5i1.41

Ridley, D. (2008) Multiple Purposes of Literature Review. London: Sage.

Samraj, B. (2013) 'Form and function of citations in discussion sections of Master's theses and research articles', Journal of English for Academic Purposes, Vol. 12, No. 4, pp. 299-310. https://doi. org/10.1016/j.jeap.2013.09.001

Seliger, H. W. and Shohamy, E. (1990) Second Language Research Methods, $2^{\text {nd }}$ edition, Oxford: Oxford University Press.

Soler-Monreal, C. and Gil-Salom, L. (2011) 'A cross-language study on citation practice in Ph.D. theses', International Journal of English Studies, Vol. 11, No. 2, pp. 53-75. https://doi.org/10.6018/ ijes/2011/2/149641

Swales, J. M. (1990) Genre Analysis: English in academic and research settings. Cambridge: Cambridge University Press.
Swales, J. M. (2014) 'Variation in Citational Practice in a Corpus of Student Biology Papers: From Parenthetical Plonking to Intertextual Storytelling', Written Communication, Vol. 31, No. 1, 118-141. https://doi.org/10.1177/0741088313515166

Swales, J. M. and Feak, C. B. (2004) Academic writing for graduate students: Essential tasks and skills, 2nd edition, Ann Arbor, MI: The University of Michigan Press.

Thomas S. and Hawes, T. P. (1994) 'Reporting verbs in medical journal articles', English for Specific Purposes, Vol. 13, No. 2, pp. 129 148. https://doi.org/10.1016/0889-4906(94)90012-4

Thompson, P. (2005) 'Points of focus and position: Intertextual reference in Ph.D. theses', Journal of English for Academic Purposes, Vol. 4, No. 4, pp. 307-323. https://doi.org/10.1016/j.jeap.2005.07.006

Thompson, G. and Ye, Y. (1991) 'Evaluation in the reporting verbs used in academic papers', Applied Linguistics, Vol. 12, No. 4, pp. 365 382. https://doi.org/10.1093/applin/12.4.365

Thompson, P. and Tribble, C. (2001) 'Looking at citations: Using corpora in English for academic purposes', Language, Learning and Technology, Vol. 5, No. 3, pp. 91-105. https://dx.doi. org/10125/44568

Uba, S. Y. (2020) 'Semantic Categories of Reporting Verbs across Four Disciplines in Research Articles', English Language Teaching, Vol. 13, No. 1, pp. 89-98. https://doi.org/10.5539/elt.v13n1p89 